\title{
COMUNICACÃO, IDENTIDADE E TERRITÓRIO: CAMINHOS PARA AS COMUNIDADES QUILOMBOLAS DA CACANDOCA EM UBATUBA E DO MANDIRA EM CANANÉIA
}

\author{
Adriana Rabelo Rodrigues Marcelo* \\ Renata Castro Cardias** \\ Universidade Metodista de São Paulo - UMESP
}

RESUMO

$\mathrm{O}$ artigo tem, como proposta, analisar como as comunidades quilombolas tanto da Caçandoca, em Ubatuna, quanto do Mandira, em Cananéia, cidades do litoral norte e sul do Estado de São Paulo, respectivamente, reivindicam seus direitos enquanto movimentos sociais. Através de pesquisa bibliográfica, o trabalho debaterá sobre temáticas, como comunidades, identidades culturais, cidadania, comunicação, movimentos sociais e território. Verificamos que ambas as comunidades estudadas sofrem ameaças relativas ao seu território devido à especulação imobiliária, ao autoritarismo ambiental e ao turismo predatório. Enquanto cultura de resistência, as iniciativas de comunicação comunitária, nos quilombos em questão, constituem caminhos que auxiliam a luta pelos seus territórios. O direito à terra assegura suas identidades, suas culturas e o desenvolvimento comunitário, a partir da elaboração de suas próprias narrativas.

Palavras-chaves: cidadania; comunicação comunitária; comunidade; identidade; quilombolas.

* Bacharel em Jornalismo e Especialista em Assessoria, Gestão da Comunicação e Marketing pela Universidade de Taubaté, UNITAU, e mestranda pelo Programa de Pós-Graduação em Comunicação Social da Universidade Metodista de São Paulo. Bolsista CNPQ, e-mail: adrianarodrig@gmail.com

** Bacharel em Turismo e Mestre em Comunicação pela UNIP (Universidade Paulista), Especialista em Gestão Cultural pelo SENAC-RJ e em Cidades e Empreendimentos Criativos pela Universidade Nacional de Córdoba -AR, Doutoranda em Comunicação Social pela Universidade Metodista - UMESP). E-mail: rcardias@gmail.com. 


\section{INTRODUCÃO}

$\mathrm{Na}$ contemporaneidade, a globalização e a hegemonia apresentam, em suas manifestações na sociedade, uma face perversa que limita e exclui pessoas a partir de padrões de comportamento, marginalizando, dessa forma, grupos e/ou populações inteiras, fato que traz consequências na conquista e no exercício de seus direitos, principalmente os relacionados à cidadania.

A dinâmica entre o global e o local cria e recria identidades, reavivando uma pluralidade sociocultural mediante o processo de globalização. Nessa perspectiva, diferentes movimentos sociais buscam, através de articulações e de parcerias, superar a opressão e a exploração, oriundas dos grupos hegemônicos, e conquistar a liberdade, a igualdade e a justiça social.

No entanto ainda nos deparamos com uma série de tensões sociais marcadas pelas desigualdades e pela discriminação de minorias, fatos que constituem exemplos de violação dos Direitos Humanos. Infelizmente, essas expressões consistem em flagelos que acompanham a dinâmica de um processo de globalização contraditório, desigual e excludente. A violência (física ou simbólica) constitui um dos efeitos colaterais de um sistema pautado na lógica da produção/consumo de bens e de serviços, em ideias e em configurações identitárias homogêneas e pasteurizadas, de um modo de vida global, que impacta a vida de milhares de pessoas no mundo.

Muitos desses conflitos relacionam-se diretamente tanto com os direitos humanos, quanto com as identidades, que, nesse caso, compreendem-se como um conjunto de conhecimentos de língua e de outros aspectos culturais que permitem, aos sujeitos, reconhecer e estabelecer vínculos com determinado grupo social.

No Brasil, a configuração cultural que edifica nosso mosaico identitário é híbrida, desigual e formada por ajustamentos e por intensos embates entre diferentes povos. Dentre tantas identidades, a sociedade define algumas como tradicionais, muitas vezes, essas populações são marginalizadas. Essa parcela "excluída" encontrou, na resistência cultural, a capacidade de se articular para defender suas características naturais e culturais.

O grande marco da proteção identitária foi a Constituição Federal de 1988, por ter reconhecido, em seu artigo $215, \mathbb{S} 1 .^{\circ}$, que as manifestações das culturas pertencentes ao processo civilizatório nacional - principalmente, culturas indígenas e afro-brasileiras — receberiam proteção especial. O documento definiu, ainda, em seu artigo 216, inciso II, os modos de criar, de fazer e de viver como parte do bem ambiental cultural imaterial. Posteriormente, o decreto $\mathrm{n}^{\circ}$ 6.040, de 07 de fevereiro de 2007, definiu povos e comunidades tradicionais brasileiras como: 
Grupos culturalmente diferenciados e que se reconhecem como tais, que possuem formas próprias de organização social, que ocupam e usam territórios e recursos naturais como condição para sua reprodução cultural, social, religiosa, ancestral e econômica, utilizando conhecimentos, inovações e práticas gerados e transmitidos pela tradição.(...) entre eles estão Povos Indígenas, Quilombolas, Seringueiros, Castanheiros, Quebradeiras de Cocode-babaçu, Comunidades de Fundo de Pasto, Faxinalenses, Pescadores Artesanais, Marisqueiras, Ribeirinhos, Varjeiros, Caiçaras, Praieiros, Sertanejos, Jangadeiros, Ciganos, Açorianos, Campeiros, Varzanteiros,Pantaneiros, Geraizeiros, Veredeiros, Caatingueiros, Retireiros do Araguaia, entre outros.” (PNPCT, 2007)

Porém, apesar do "reconhecimento" governamental, os povos e as comunidades tradicionais têm dificuldades para garantir sua permanência em seus territórios, visto que são, constantemente, ameaçados por pecuaristas, por incorporações imobiliárias e, até mesmo, pelo autoritarismo ambiental do Estado.

Diante dessa realidade, a comunicação tornou-se a principal forma de preservar a identidade e a cultura. Porém, por meio da evolução tecnológica e da industrialização, acentuou-se a discriminação de grupos considerados subalternos, especialmente, nos países que adotaram o capitalismo como sistema econômico. Nesse ambiente, marcado pelas lutas por dignidade e direito à cidadania, surge, entre as décadas de 1960 e 1970 , a pauta sobre o direito à comunicação no mesmo contexto em que diversos movimentos populares reivindicaram o reconhecimento de direitos econômicos e sociais.

Portanto, é cada vez mais necessário tratar o direito à comunicação como elemento essencial para a conquista da liberdade e da democracia, contanto que esse fluxo comunicacional ocorra num sentido de mão dupla e contenha intercâmbio, acesso e participação popular.

\section{QUILOMBOLAS ENQUANTO MOVIMENTO SOCIAL: LUTAR E RESISTIR}

Como vimos, os territórios, além de assegurar a sobrevivência dos povos e das comunidades "tradicionais", constituem a base para a produção e para a reprodução de todo o seu patrimônio cultural.

Apesar das legislações existentes e das poucas políticas e ações práticas voltadas ao desenvolvimento e à preservação desses povos, eles são segregados socialmente e não participam dos processos de democratização da comunicação. Porém, perante um panorama desfavorável, tais comunidades resistem e lutam para que sejam inseridas e reconhecidas nos processos de elaboração de bens simbólicos e na circulação de suas narrativas identitárias. 
O Brasil carrega, em seu desenvolvimento histórico, tristes marcas da segregação e da discriminação raciais advindas, especialmente, do período da escravatura, iniciada com as expansões comerciais europeias no século XV. Até o século XIX, aproximadamente, 12 milhões de africanos foram transportados para o continente americano em um contexto de tráfico atlântico. Tanto os colonizadores, quanto os traficantes, negavam a diversidade das pessoas estigmatizadas como "africanos" ou como "escravos" e ignoravam as culturas complexas dos diversos grupos aos quais pertenciam os indivíduos trazidos à América em condições desumanas.

De acordo com um levantamento disponível no site do Instituto Brasileiro de Geografia e Estatística (IBGE), realizado em comemoração aos 500 anos do Brasil, cerca de quatro milhões de africanos, entre homens, mulheres e crianças, chegaram ao país, entre o século XVI e meados do XIX. O documento afirma que aquele número equivale a mais de um terço de todo o comércio clandestino de africanos. A força de trabalho, dessa população, nos engenhos de açúcar, nas minas e em outras atividades econômicas, tornou-se indispensável para a manutenção do sistema colonial, vigente até meados do século XIX. Indivíduos de diferentes etnias, compulsoriamente trazidos e submetidos aos traumas das viagens transatlânticas insalubres e a uma nova realidade, buscaram alternativas de sobrevivência.

Mesmo com toda a violência à qual eram sujeitos, os africanos trouxeram e preservaram elementos de sua cultura. Num processo de hibridação, formaram novos códigos culturais gerados pelas interações, que foram somadas à materialidade do mundo colonial e às tentativas de imposição do catolicismo de matriz europeia. Naquele ambiente, existiam formas de resistência tanto individuais, quanto coletivas, como a formação de quilombos (ou mocambos), nos quais a população escravizada se refugiava. Geralmente, de difícil acesso, ficavam em regiões montanhosas ou de matas fechadas, havendo, ainda, os quilombos de doação e/ou herança, espaços adquiridos por comunidades negras.

Os quilombos também podem ser compreendidos como meios, através dos quais, os africanos se refugiavam e recuperavam sua identidade cultural, portanto, constituíam espaços de resistência.

O tempo passou, mas os problemas relacionados à exclusão e à discriminação continuaram. Até a década de 1970, os territórios reconhecidos como originários de quilombos ainda estavam associados à escravidão, a um espaço de fuga e de isolamento de povos negros. Essa concepção não considerava as relações existentes entre escravistas e escravos, nem as diferentes formas de quilombos existentes nas diversas regiões do país. 
$\mathrm{Na}$ mesma década, várias entidades negras se organizaram, com destaque para o Movimento Negro Unificado. Somente, em 1988, após um período de ditadura militar (1964-1985), surgiram políticas públicas sociais de valorização voltadas à democracia e à igualdade racial. Verificamos que, nesse período, muitas comunidades quilombolas começaram a ser reconhecidas.

Gomes e Reis (1996), autores do livro Liberdade por um fio: história dos quilombos no Brasil, conceituaram quilombo como "campo de negro", termo que pode ser entendido como:

Uma complexa rede social permeada por aspectos multifacetados que envolveram - em determinadas regiões o Brasil — inúmeros movimentos sociais e práticas econômicas com interesses diversos (GOMES, F; REIS,J,1996,p.36)

Os pesquisadores João José Reis e Flávio dos Santos Gomes abordam a relação dos quilombos com as questões culturais e de empoderamento, as diferenças existentes nesses locais e os movimentos sociais que questionavam a realidade na qual estavam inseridos.

A partir da Constituição de 1988, o conceito de comunidades quilombolas passou por reformulações que culminaram na denominação remanescente de quilombos. Carril (1997), em sua obra Terra de Negros, explica que

Os quilombos eram, tradicionalmente, agrupamentos formados por escravos fugidos, em locais isolados e de difícil acesso. Atualmente, o termo passou a designar as terras habitadas por negros e originadas de doações de antigos senhores, de fazendas abandonadas com escravos, de terras de igreja, e, com o decreto da abolição, terras doadas a ex-escravos (CARRIL, 1997, p.10)

Já Arruti (2006), em Mocambo: antropologia e história do processo de formação quilombola, afirma que o termo remanescente surgiu como uma solução encontrada para a questão de "continuidade e descontinuidade", presente nas comunidades quilombolas tanto do passado, quanto da contemporaneidade. Atualmente, a denominação é utilizada para dotar esses grupos de direitos, do ponto de vista jurídico.

A Fundação Cultural Palmares, criada em 1988, surgiu para realizar ações de promoção à igualdade racial e de valorização à cultura africana e afro-brasileira. Além disso, assumiu a responsabilidade de reconhecer as comunidades remanescentes quilombolas, que, para serem certificadas, precisam enviar uma declaração de autorreconhecimento como "remanescente de quilombos". Após a entrega do documento, ocorre o processo de análise para a emissão da "Certidão de Autorreconhecimento". Porém a luta qui- 
lombola não termina com a conquista do documento que a certifica, pois é necessário, também, a sua titulação.

De acordo com o artigo 68 da Constituição Federal (1988), "aos remanescentes das comunidades dos quilombos que estejam ocupando suas terras, é reconhecida a propriedade definitiva, devendo o Estado emitir-lhe os títulos respectivos." Embora o artigo aponte o direito à terra para as comunidades quilombolas, assim como repara séculos de exclusão social, as comunidades continuam com dificuldades devido à burocracia. São muitos os obstáculos, desde o processo de mapeamento das terras, até a análise para a emissão do Relatório Técnico de Identificação e Delimitação do território (RTID).

Em 1995, o quilombo Boa Vista, no Pará, foi a primeira comunidade quilombola titulada pelo Instituto Nacional de Colonização e Reforma Agrária (INCRA).

O ano de 2003 marcou a trajetória das comunidades remanescentes de quilombo, pois se puderam autodeclarar a partir do direito concedido pelo Decreto Federal no 4887, assinado no dia 20 de novembro daquele ano, o qual criou a Secretaria de Políticas de Promoção da Igualdade Racial, cujo objetivo consiste em formular, em coordenar e em articular políticas de valorização da igualdade racial e de inclusão de comunidades tradicionais.

Ainda em 2003, passou a vigorar a lei $\mathrm{n}^{\circ} 10.639$, a qual estabelece o ensino de História e Cultura Afro-brasileira e Africana, que abrange a luta dos negros em nosso país. A legislação também engloba questões relacionadas à cultura negra brasileira e suas contribuições nas áreas social, econômica e política.

Porém, apesar das políticas públicas existentes, a população afrodescendente ainda sofre com a marginalização e com o desrespeito. De acordo com a Fundação Cultural Palmares (2012), existem mais de 1.500 comunidades espalhadas pelo Brasil. A negação do próprio preconceito e a consciência de que existem inúmeras violações de seus direitos, fazem, da luta quilombola, uma possibilidade de conhecer a sua participação na construção da cultura brasileira.

\subsection{A IDENTIDADE E O SENTIDO DE COMUNIDADE NOS TERRITÓRIOS QUILOMBOLAS}

A vida em comunidade sempre constituiu o elo que garantiu a sobrevivência da maioria dos povos. Nos quilombos, a situação não foi diferente. A necessidade de preservar a vida em detrimento dos casos de violência, motivou a fuga ou o isolamento de escravos, que encontraram, na vida em comunidade, a chance de manter suas heranças culturais e garantir a própria existência.

O conceito de comunidade quilombola sofreu alterações no decorrer do tempo, pois, a sociedade, os órgãos representativos e as instituições, 
que trabalham em defesa das causas territoriais étnicas, lutaram para que fossem incluídos, na Constituição Federal, os direitos de propriedade e de reconhecimento dos grupos excluídos, humilhados e devastados ao longo da história do Brasil.

Os territórios conquistados, por direito, pelos descendentes de escravos, demarcam não apenas o espaço territorial, mas também um ambiente repleto de significados históricos. Nesse sentido, a união de diferentes elementos sociais e suas influências na condução da história da humanidade compõem a cultura de um povo. Stuart Hall (2008) define cultura a partir da "dialética entre ser e a consciência social" como

sentidos de valores que nascem entre as classes e grupos sociais diferentes, com base em suas relações e condições de existência e respondem a estas; e também como as tradições práticas vividas através das quais esses 'entendimentos' são expressos e nos quais estão incorporados (HALL, 2008. p. 133).

Em ambientes diversificados e, muitas vezes, complexos, os indivíduos, munidos de sua bagagem histórica e cultural, buscam a sua identidade como forma de fortalecer a presença dentro do grupo e consolidar sua relação com o mundo. Hall analisa aspectos diferentes da cultura e sua relação com a identidade. Para ele:

[...] a identidade é, na verdade, algo formado ao longo do tempo através de processos inconscientes, mais do que algo inato à consciência, desde o nascimento. Há sempre algo "imaginário" ou fantasiado sobre essa unidade. Ela parece sempre incompleta, está sempre "em processo", sempre "sendo formada". [...] Assim, ao invés de falarmos da identidade como algo concluído, deveríamos falar de identificação, e vê-la como um processo em andamento. A identidade surge não tanto na plenitude da identidade já presente dentro de nós enquanto indivíduos, mas da insuficiência de totalidade, que é "preenchida" a partir do que nos é exterior, pelas formas como imaginamos sermos vistos por outros (HALL, 1988, p. 30).

Para que os vínculos de uma comunidade sejam mantidos, é necessário que o grupo encontre meios de recuperar suas relações com o passado e se adapte às mudanças.

Gustavo Quesada (1980) relaciona a existência da comunidade ao "povo que nela reside ou se identifica". O autor também trata da relação da comunidade com os aspectos da identidade. Ele diz que: 
É bom notar-se que quando várias pessoas comungam da mesma realidade ou se identificam com experiências semelhantes, isto é fator de união e de integração. É necessário tocar o âmago dessa identidade para poder obter ações comunais como um todo. Mesmo que qualquer comunidade possa se dividir em subcomunidades, representando constituintes com interesses vários um dos outros, há laços comuns entre si que atingem a periferia da comunidade (QUESADA, 1980, p. 14).

Tanto o vínculo territorial, quanto as heranças culturais, estruturam a identidade de um determinado grupo. No caso das comunidades remanescentes de quilombo, a manutenção desses aspectos também interfere, diretamente, na permanência desses povos nos territórios por eles conquistados, direito garantido por lei.

\subsection{QUILOMBOS DO LITORAL SUL DO ESTADO DE SÃO PAULO: O CASO DA COMUNIDADE QUILOMBOLA DO MANDIRA}

Dados de 2012, do Instituto de Terras de São Paulo (ITESP), indicam que, atualmente, existem 66 comunidades quilombolas identificadas no Estado de São Paulo. Das 28 comunidades do estado, 21 estão no Vale do Ribeira. Desse total, apenas seis foram tituladas conforme a legislação em vigor.

De acordo com o Instituto Socioambiental (ISA), através do Inventário cultural de quilombos do Vale do Ribeira (2013), as comunidades quilombolas que ocupam a região, existem há 300 anos. Após a decadência da mineração de ouro e, mais tarde, das lavouras de arroz, muitos trabalhadores — antes escravos - se fixaram em terras abandonadas pelos fazendeiros, formando comunidades negras existentes até hoje. Boa parte delas espraiam-se ao longo das duas margens do Rio Ribeira de Iguape, entre os municípios de Iporanga e Eldorado.

No início da década de 1970, houve uma tentativa de regularização fundiária das posses rurais por meio de um convênio entre a Superintendência para o Desenvolvimento do Litoral Paulista (Sudelpa) e a Procuradoria do Patrimônio Imobiliário. Naquele momento, teve início a demarcação de terras e a distribuição de títulos de propriedade a pequenos posseiros no Vale do Ribeira. Porém, essa forma de "demarcação", desconsiderava a existência de terras comunais, permitindo que fossem loteadas.

Já na década de 1980, o governo do Estado de São Paulo investiu em melhorias nas estradas que dão acesso à região, a fim de integrá-la ao resto do estado. As terras se valorizaram e a especulação imobiliária se instalou, despertando interesse de latifundiários e de empresários de outras regiões, fato que agravou conflitos fundiários em diversas áreas do Vale. Naquele 
período, o governo estadual começou a se apoiar nas organizações sociais existentes na região, visando a implementar, timidamente, políticas de desenvolvimento rural, além disso, também foram criadas muitas das Unidades de Conservação do local. Afora o autoritarismo ambiental, verificamos a falta de avanço no processo de reconhecimento das comunidades quilombolas e de seus territórios, além de ameaças permanentes de retrocesso no marco legal que garante direitos constitucionais.

De acordo com o Inventário Cultural de Quilombos do Vale do Ribeira (2013), a comunidade do Mandira está localizada no município de Cananéia e seu acesso é possível pela estrada do Itapitangui/Ariri, que sai da estrada Jacupiranga-Cananéia antes da balsa. Posteriormente, é preciso percorrer a Estrada do Mandira até a altura do Km 11.

Em uma área de 2.880 hectares, são encontrados dois ambientes, um de terra firme, que está bastante preservado, possui 1.705 ha e é coberto, em sua maior parte, com Mata Atlântica. Já, o outro, de mangue, possui 1.175 ha, área que foi oficialmente reconhecida como a Reserva Extrativista (Resex) do Mandira, em 2002, para regulamentar a extração e a engorda de ostras de caranguejos e de peixes (ISA, site Quilombos do Ribeira).

Em 2008, a população era de 108 pessoas, composta por 54\% do sexo feminino e, 46\%, do masculino, estando, menos da metade do total, com idade acima de 30 anos (ISA, 2008) naquela época. A formação da comunidade ocorreu no século XIX, em 1868, quando Francisco Mandira recebeu cerca de 2.880 hectares, doados pela sua meia irmã, Celestina Benícia de Andrade.

Em 1974, a comunidade foi pressionada a vender boa parte de seu território e, os herdeiros que se recusaram, precisaram ceder metade de suas terras como pagamento pela regularização fundiária e foram realocados para outra parte do antigo território (Turatti, 2002). A partir de 1993, apoiados pelo Núcleo de Apoio à Pesquisa sobre Populações Humanas e Áreas Úmidas Brasileiras da USP (NUPAUB/USP), as famílias de Mandira passaram a trabalhar para implementar uma Reserva Extrativista em seu território.

Em 1994, fundou-se a Associação dos Moradores da Reserva Extrativista do Bairro Mandira e, em 1998, a Cooperostra, uma cooperativa para comercializar as ostras coletadas na Resex. Esse processo de organização culminou com a oficialização da Resex, em 2002, mesmo ano em que o Itesp reconheceu Mandira como uma comunidade remanescente de quilombo. Em 2010, Mandira aprova seu plano de manejo e ganha a Concessão do Direito Real de Uso da área, renovável após 20 anos (Andrade, 2011).

No quilombo do Mandira não há rádio, jornal ou TV comunitários. Contudo existem processos comunicacionais significativos tanto de forma espontânea, através das suas expressões culturais, quanto por meio de diversas 
iniciativas na elaboração de conteúdos e de narrativas alternativas. As ações comunicacionais possuem a limitação do tempo, visto que dependem da aprovação de projetos via editais públicos. Entretanto não podemos deixar de reconhecer que elas são importantes no contexto local, já que valorizam a cultura e preservam a memória e a identidade da população.

\subsection{QUILOMBOS DO LITORAL NORTE DE SÃO PAULO: O CASO DA COMUNIDADE QUILOMBOLA DA CACANDOCA}

A história da comunidade remanescente de quilombo da Caçandoca, localizada na cidade de Ubatuba, litoral norte de São Paulo, é marcada por uma trajetória de conflitos e de conquistas. No entanto sua origem foge às características mais conhecidas de definição de quilombos, normalmente, identificados como territórios de fuga de escravos, visto que a Caçandoca constitui terra de doação.

A antiga fazenda foi comprada por José Antunes de Sá, em 1858. O trabalho escravo mantinha suas atividades agrícolas, como o cultivo do café e da cana-de-açúcar. Com o fazendeiro, também estavam seus três filhos, Marcolino, Isídio e Simphonio, que, além de ajudarem o pai a administrar a Caçandoca, também tiveram filhos com as escravas, conforme revela o Relatório Técnico-Científico do ITESP, de 2000. A maioria dos descendentes dessas relações permaneceu na fazenda, mantendo forte vínculo com o local.

O Relatório Técnico-Científico do ITESP também aponta que, após a abolição da escravatura, em 1888, alguns negros livres deixaram a fazenda para tentar a vida em outros lugares. No local, permaneceram os herdeiros, mesmo que não reconhecidos oficialmente, além dos demais ex-escravos que já residiam no local.

Atualmente, 200 pessoas, distribuídas em 40 famílias, vivem na comunidade que ocupa uma área de 890 hectares $^{1}$. No entanto existem aquelas que residem fora do local, mas têm direito sobre a terra, pois também são herdeiras.

Historicamente, os herdeiros da Caçandoca enfrentaram sérios problemas com a especulação imobiliária e com os posseiros, devido à riqueza natural do lugar, em que se inserem as praias da Caçandoca, da Caçandoquinha, do Saco do Morcego, do Saco da Raposa e do Simão, além do Bairro Alto.

\footnotetext{
O Relatório Técnico-Científico do ITESP, produzido no ano 2000, explica a forma de divisão de terras da Comunidade Remanescente de Quilombo. O texto diz que: "O território está atualmente dividido em trinta e quatro glebas, sendo onze no nome de pessoas da comunidade onde residem 17 famílias. Das vinte e três glebas restantes, três correspondem às duas escolas municipais e à igreja, construída pela Comunidade em 1962, de propriedade da Mitra Diocesana de Santos. Existem, ainda, benfeitorias em outras cinco glebas, e nas outras quinze não existe nenhuma forma de ocupação".
} 
Em 1974, vários membros da comunidade foram ameaçados, expulsos e tiveram suas casas destruídas, situação que desestabilizou o grupo e provocou o afastamento de muitos de seus membros que, devido à pressão, deixaram a comunidade.

Em 2000, a Fundação Instituto de Terras do Estado de São Paulo (ITESP) elaborou o Relatório Técnico-Científico, integrante do processo que favoreceu o reconhecimento das terras da antiga fazenda da Caçandoca como comunidade negra rural remanescente de quilombo. Em dezembro de 2005, o Instituto Nacional de Colonização e Reforma Agrária (INCRA) emitiu o parecer de posse aos herdeiros. No entanto, tal conquista, não impediu as especulações e as invasões.

As experiências negativas do passado comprometeram os vínculos culturais e de ancestralidade dos membros da comunidade, fazendo com que os sentimentos de pertencimento e de coletividade sofressem danos que prejudicaram, inclusive, a comunicação do grupo. A situação dividiu os herdeiros e favoreceu o surgimento de um ambiente de conflitos motivados pela disputa de poder. Tanto que, inicialmente, havia duas associações, uma em Santos, cidade para onde migraram vários herdeiros e, outra, em Ubatuba. Por orientação do ITESP e da promotoria da justiça, as duas associações se uniram, em 2013, para evitar a perda do território. Em virtude de desentendimentos, muitas tradições, como as festas religiosas católicas e as atividades culturais, antes, fortemente, difundidas na comunidade, estão acabando. Apesar disso, algumas atividades, como o mutirão, as brincadeiras de roda, a roda de histórias, as festas religiosas, as oficinas de artesanato e de ervas medicinais ainda acontecem, mas sem muito envolvimento da comunidade.

Nesse ambiente instável, existem muitas dificuldades para uma vida focada num objetivo comum entre os herdeiros, visto que a força da relação com o ambiente está limitada ao domínio territorial. O que, antes, era um espaço de resistência, passou a ser de rivalidade e de interesses pessoais e, por essa razão, os herdeiros distanciaram-se de suas tradições culturais.

Apesar das dificuldades de relacionamento existentes na Caçandoca, é possível perceber que a vida em comunidade acontece, mesmo que de maneira um pouco tímida. Isso, porque seus membros sabem da história de seus antepassados e se reconhecem nesse contexto. A recuperação do senso de coletividade e das lutas por um objetivo comum, bem como um ambiente organizado, favorável para a manutenção da comunidade, constituem fatores vitais para que os moradores não percam o direito sobre o território.

2. A comunicação comunitária em defesa do território e da cidadania

O direito à comunicação tem valor universal e não deveria ser apenas usado como mecanismo de manipulação ideológica a favor de grupos domi- 
nantes. Nos princípios democráticos, que também envolvem as mídias e o direito de expressão, os receptores se tornam emissores, já que se posicionam, se empoderam e bradam suas vozes na luta incansável para exercer sua cidadania. Cria-se, portanto, a concepção de espaços sociais de luta, reais e virtuais, representados pelos movimentos sociais, conforme afirmou Liszt Vieira, em Cidadania e Globalização (2000),

A democracia não é apenas um regime político com partidos e eleições livres. É sobretudo uma forma de existência social. Democrática é uma sociedade aberta, que permite sempre a criação de novos direitos. Os movimentos sociais nas lutas, transformaram os direitos declarados formalmente em direitos reais. As lutas pela liberdade e igualdade ampliaram os direitos civis e políticos da cidadania, criaram os direitos sociais, os direitos das chamadas minorias - mulheres, crianças, idosos, minorias étnicas e sexuais- e pelas lutas ecológicas, o direito ao meio ambiente sadio. (VIEIRA, 2000, p.39-40).

Mesmo com todos os problemas que acompanham a história das Comunidades Remanescentes de Quilombo do Mandira e da Caçandoca e interferem na constituição da comunidade como um espaço de coletividade e de lutas por objetivos comuns, percebem-se brechas que poderiam favorecer o entrosamento entre os membros da comunidade, além de fortalecer os elos históricos que unem os herdeiros.

Levando em conta a realidade do local, podemos perceber o quanto a história interfere no processo de comunicação dos dois grupos quilombolas. Originalmente, os membros das comunidades precisavam da comunicação para manter sua cultura e sua identidade na nova terra que habitavam quando ainda eram escravos. Era uma forma de manter suas origens.

$\mathrm{Na}$ atualidade, seus costumes e formas de comunicação sofreram alterações devido, inclusive, aos avanços tecnológicos. Todavia a necessidade de manter viva suas heranças culturais permanece. Num processo evolutivo do grupo, outros caminhos foram encontrados e outros sentidos de ser e de estar foram incorporados entre os herdeiros. No entanto a comunicação continua sendo o principal caminho para a manutenção dos herdeiros enquanto remanescentes de quilombo, pois precisam garantir a permanência do grupo no local conquistado por direito.

Apesar das tentativas de manutenção da cultura local, por meio de atividades culturais esporádicas, há sinais de que existem falhas de comunicação entre os quilombolas, agravadas pelas especulações em tornos dos territórios e, no caso da Caçandoca, pelos desentendimentos entre os membros da comunidade. 
Mesmo diante dos problemas enfrentados, é nítida a preocupação do Mandira e da Caçandoca em manter o direito dos herdeiros sobre os territórios, situação que está sempre em debate pelo fato de ainda haver grande interesse de posseiros e de especuladores imobiliários.

Fundamentada na importância da apropriação dos mecanismos de comunicação por parte dos indivíduos e de seus grupos, a pesquisadora Cicilia Peruzzo apresenta a comunicação popular como um canal de mão dupla, no qual os envolvidos assumem, de fato, o seu papel social.

A comunicação popular tem como protagonista o próprio povo e/ou as organizações e pessoas a ele ligadas organicamente. Nesse caso, ele é visto no seu antagonismo em relação às classes dominantes e concebido como o conjunto das classes subalternas" (PERUZZO, 2004, p.127).

Peruzzo (2002) acredita que um dos caminhos para a emancipação dos indivíduos e para o exercício da cidadania está no acesso à comunicação e no domínio das técnicas que podem ser utilizadas na difusão de movimento de luta, de resistência e de conscientização, num processo de comunicação informal.

Nesse sentido, a comunicação comunitária assume um papel fundamental na promoção da cidadania, uma vez que os envolvidos em ações de práticas de comunicação, ganham voz e, também, dão voz às minorias e aos grupos marginalizados pela sociedade.

A comunicação comunitária que vem sendo gestada no contexto dos movimentos populares é produzida no âmbito das comunidades e de agrupamentos sociais com identidades e interesses comuns. É sem fins lucrativos e se alicerça nos princípios de comunidade, quais sejam: implica a participação ativa, horizontal e democrática dos cidadãos; a propriedade coletiva; o sentindo de pertença que desenvolve entre os membros; a co-responsabilidade pelos conteúdos emitidos; a gestão partilhada; a capacidade de conseguir identificação com a cultura de interesses locais; o poder de contribuir para a democratização do conhecimento e da cultura (PERUZZO, 2007, p. 5).

Focada nos interesses de grupos específicos, a comunicação comunitária tem a missão de fomentar a prática da cidadania, pois traz, aos indivíduos, a responsabilidade para com os seus deveres. Mesmo tendo, como princípio, a comunicação horizontal, o espaço de troca de conhecimentos também enfrenta conflitos, visto que, se adequar à liberdade, requer debate e um 
importante aprendizado de saber ouvir e respeitar as diferentes opiniões, religiões, posicionamentos políticos e ideológicos.

Para as comunidades estudadas, a prática da comunicação comunitária fortalece o sentido de pertencimento, de união e de luta pela preservação das culturas, da história e do amadurecimento político. Para Cicilia Peruzzo (2002), a comunicação constitui um caminho para o fortalecimento da identidade e da conquista de espaços de articulação social.

As lideranças das comunidades remanescentes de quilombo do Mandira e da Caçandoca vem percebendo o quanto uma ação colaborativa de comunicação pode ser eficiente e emancipadora. Independente dos interesses particulares de cada grupo que tem direitos sobre o local, existem os interesses coletivos, os quais podem ser difundidos e debatidos entre todos.

\section{CONSIDERACÕES FINAIS}

Como vimos, é cada vez mais necessária a busca pelo direito à comunicação para conquistar a liberdade e a democracia. Nesse sentido, faz-se necessário, mais do que nunca, trocar informações e promover o intercâmbio, o acesso e a participação.

Expressar sua cultura, assim como produzir e difundir narrativas pelas perspectivas e percepções dos diferentes grupos sociais, constitui um exercício democrático. Considerando as comunidades tradicionais estudadas, o direito de apresentar seus sistemas de representações significa, também, um exercício de cidadania, visto que possibilita o estreitamento dos laços comunitários e identitários, além da criação de novas políticas públicas de preservação e de valorização cultural desses povos.

Apesar das poucas iniciativas voltadas à comunicação "de" e "para" as comunidades tradicionais, até o momento não há projetos que viabilizem o uso de ferramentas de comunicação comunitária nos quilombos estudados. Contudo as possibilidades de ações são fundamentais, já que a luta pelo direito à comunicação também está presente na pauta de reivindicações dessas populações.

As restrições e a pulverização de políticas públicas voltadas à comunicação e ao reconhecimento da diversidade cultural, possibilitam uma produção pequena, com limitações, todavia importantes para essas comunidades. Tais iniciativas podem ser importantes também para investigar a compreensão de projetos e de narrativas identitárias realizadas pelos olhares quilombolas.

\section{REFERENNCIAS}

ARRUTI, José Maurício. Mocambo: antropologia e história do processo de formação quilombola. Bauru, SP: EDUSC, 2006. 
CARRIL, Lourdes. Terra de negros. São Paulo: Scipione, 1997.

HALL, Stuart. A questão da cultura. Tradução de Andréa B. M. Jacinto e Simone M. Frangella. 2 ed. Campinas-SP: IFC/ UNICAMP, 1998.

IBGE. Brasil 500 anos: território brasileiro e povoamento. 2016. Disponível em: $<<$ http://brasil500anos.ibge.gov.br/territorio-brasileiro-e-povoamento/negros.html>>. Acesso em: 15 jan. 2016.

ITESP. Relatório técnico-científico sobre os remanescentes da comunidade de Camburi - Ubatuba-SP. Abril/ 2002.

INSTITUTO SOCIOAMBIENTAL. Inventário Cultural dos Quilombos do Vale do Ribeira 2013. Disponível em: $<<\underline{\text { http://www.socioambiental.org/sites/blog.socioambiental.org/files/publicacoes/ }}$ pdfpublicacao-final inventario.pdf $>>$. Acesso em $20 \mathrm{dez} .2015$.

MINISTÉRIO DO MEIO AMBIENTE. Política Nacional de Desenvolvimento Sustentável dos Povos e Comunidades Tradicionais. Disponível em: $\quad<<$ http://www.mma.gov.br/desenvolvimentorural/ terras-ind\%C3\%ADgenas,-povos-e-comunidades-tradicionais.>> Acesso em 20 dez. 2015.

PERUZZO, Cicilia. Comunicação nos Movimentos Populares: a participação na construção da cidadania. $3^{\mathrm{a}}$ ed. Rio de Janeiro: Editora Vozes, 2004.

. Comunicação comunitária e educação para a cidadania. PCLA, v. 1, p. 1-15, 2002. 1-29, 2007.

Direito à comunicação comunitária, participação popular e cidadania. Lumina, v. 1, p.

QUESADA, Gustavo. Comunicação e Comunidade: mitos da mudança social. São Paulo: Loyola, 1980.

VIEIRA, Liszt. Cidadania e Globalização. Rio de Janeiro: Record,2000. 